\title{
Thermochemistry of Aluminum Species for Combustion Modeling from $A b$ Initio Molecular Orbital Calculations
}

\author{
MARK T. SWIHART \\ Department of Chemical Engineering, University at Buffalo (SUNY), Buffalo, NY 14260-4200, USA
}

and

LAURENT CATOIRE

Laboratoire de Combustion et Systèmes Réactifs (LCSR), CNRS, and University of Orleans, 1C, av. de la Recherche Scientifique, 45071 Orleans Cedex 2, France

\begin{abstract}
High accuracy $a b$ initio methods for computational thermochemistry have been applied to aluminum compounds expected to be present during combustion of aluminum particles. The computed enthalpies of formation at $298.15 \mathrm{~K}$ agree well with experimental values from the literature for $\mathrm{AlCl}, \mathrm{AlCl}_{3}, \mathrm{AlO}, \mathrm{AlOAl}$, linear $\mathrm{OAlO}$, planar $\mathrm{Al}_{2} \mathrm{O}_{2}, \mathrm{AlOH}, \mathrm{AlH}$, and $\mathrm{AlN}$. The agreement is fair for $\mathrm{AlCl}_{2}$. Major revisions to the recommended thermochemistry must be considered for $\mathrm{OAlCl}, \mathrm{OAlH}, \mathrm{OAlOH}$, and $\mathrm{AlC}$. This is not surprising since the thermodynamic data for $\mathrm{OAlCl}, \mathrm{OAlH}, \mathrm{OAlOH}$, and $\mathrm{AlC}$ are given in the literature as rough estimates. Calculated thermochemical data are also presented for several species never studied experimentally, including $\mathrm{AlH}_{2}, \mathrm{AlH}_{3}, \mathrm{AlOO}$, cyclic- $\mathrm{AlO}_{2}$, linear $\mathrm{AlOAlO}, \mathrm{AlHCl}, \mathrm{AlHCl}_{2}$, and others. Based on the performance of the CBS-Q and G2 methods observed in other systems, the calculated enthalpies of formation would be expected to be accurate to within \pm 1 to $2 \mathrm{kcal} \mathrm{mol}^{-1}$. However, relatively large differences between the results from the CBS-Q and G2 methods for the aluminum oxides indicate that the uncertainties are slightly larger for these compounds. The thermochemistry proposed here is shown to predict substantially different equilibrium composition from the thermochemistry previously available in the literature. (c) 2000 by The Combustion Institute
\end{abstract}

\section{INTRODUCTION}

The addition of aluminum particles to solid propellant is principally used to increase motorspecific impulse. This is due to the high heat of combustion of $\mathrm{Al}$ with various oxidizers that are encountered in practical applications, including $\mathrm{CO}_{2}, \mathrm{H}_{2} \mathrm{O}$, and $\mathrm{HCl}$. Numerous studies of aluminum combustion have been published. Most of these studies have considered the ignition and global combustion of single particles, powders, or wires in various controlled environments [1-7]. Much of this work was reviewed by Price [8].

The first numerical models of the combustion of aluminum particles neglected the finite rate chemistry of this combustion. The chemical reaction rates were assumed to be infinitely large [9-13]. However, more recent analyses of the process have provided models that include finite chemical reaction rates $[14,15]$. The combustion process involved is complicated and

*Corresponding author. E-mail: swihart@eng.buffalo.edu

0010-2180/00/\$-see front matter

PII S0010-2180(99)00128-5 therefore not easily modeled. Since aluminum burns as a vapor, the first step of this process involves gas-phase reactions between $\mathrm{Al}$ and the oxidizers, or between aluminum and reaction intermediates or reaction products. Reactions are also expected to occur on the surface of the aluminum particles, and this heterogeneous chemistry must also be included in a complete model. Under typical conditions, most of the reactions in the gas phase are in chemical equilibrium. For these conditions, the accuracy of the predictions of the gas-phase composition and temperature is determined by the accuracy of the thermochemical data for the gas-phase species. Existing thermochemical data for several species are highly uncertain, as underlined by Fontijn [16]. For some other species expected to be present, no thermochemical data are available in the literature. As a consequence, some of these species have never been introduced into kinetic models. Such species must be considered in detailed kinetic models from which reduced models are to be derived for engineering purposes.

COMBUSTION AND FLAME 121:210-222 (2000) (C) 2000 by The Combustion Institute Published by Elsevier Science Inc. 
In the present study, we report the results of high level ab initio molecular orbital calculations for the $\mathrm{Al}$ species observed, or expected to be present, in the gas phase during $\mathrm{Al}$ particle combustion with the species encountered in practical applications, namely $\mathrm{CO}_{2}, \mathrm{HCl}, \mathrm{CO}$, $\mathrm{N}_{2}, \mathrm{H}_{2}$, and $\mathrm{H}_{2} \mathrm{O}$. The computed standard enthalpies of formation are systematically compared with the available literature.

\section{COMPUTATIONAL METHODS}

Three high accuracy ab initio models for computational thermochemistry were applied to all of the aluminum compounds studied here. The first method was based on density functional theory calculations using the B3LYP functional. This functional employs Becke's gradient corrected exchange functional [17], the Lee-YangParr correlational functional [18], and three parameters fit to the original G2 test set [19]. The geometry optimization and frequency calculations for this method used the $6-31 G^{*}$ basis set. The energy at that geometry was then calculated using the $6-311+\mathrm{G}(3 \mathrm{df}, 2 \mathrm{p})$ basis set. The second method used here was the CBS-Q complete basis set method of Petersson et al. [20]. This method employs the asymptotic convergence of pair natural orbital expansions to extrapolate to the second order Moller-Plesset (MP2) limit. The higher-order contributions are then evaluated using smaller basis sets. The third method used was the Gaussian-2 (G2) model. This method approximates a quadratic configuration interaction calculation with a large basis set [QCISD(T)/6-311 + G(3df, 2p)] by combining a series of smaller calculations and assuming additivity of several components of the energy [21-23]. All of the calculations were carried out using the GAUSSIAN 94 computer program [24]. Many of the species considered here have open shell ground state electronic configurations (one or more unpaired electrons). All of the above methods use spinunrestricted wavefunctions for open shell species. These are not necessarily eigenfunctions of the spin-squared operator $\left(S^{2}\right)$, and therefore do not yield pure doublet, triplet, etc. states. They may be contaminated by states of higher spin multiplicity. This spin contamination leads to expectation values of $S^{2}$ that are greater than those of the pure spin states (i.e. $\left\langle S^{2}\right\rangle$ greater than 0.75 for doublets, greater than 2.0 for triplets, etc.). For species with mild spin contamination $\left(\left\langle S^{2}\right\rangle\right.$ within 0.05 or so of the value for the pure spin state) the above methods were found by Mayer et al. [25] to perform well. However, for more severely spin-contaminated wavefunctions, they do not give reliable predictions of thermochemistry. The effect of spin contamination on thermochemical calculations is discussed in more detail by Mayer et al. [25]. For several of the open shell species, the CBSRAD method, recommended by Mayer et al. [25] for computing high accuracy energies of free radicals, was also applied. This is a variant of the CBS-Q method, in which the geometry optimization and frequency calculation are done at the QCISD/6-31G(d) level of theory, and the larger QCISD energy calculation is replaced by a coupled-cluster $[\operatorname{CCSD}(\mathrm{T})]$ calculation. This procedure was shown by Mayer et al. [25] to give more accurate energies than the G2 or CBS-Q methods for highly spin-contaminated radical species.

The enthalpies of formation presented here were calculated based on the enthalpies of atomization computed from the ab initio calculations and the experimental heats of formation of the gas-phase atoms at $298.15 \mathrm{~K}$ and $1 \mathrm{~atm}$. (78.63 kcal/mol for $\mathrm{Al}, 52.10 \mathrm{kcal} / \mathrm{mol}$ for $\mathrm{H}$, $28.97 \mathrm{kcal} / \mathrm{mol}$ for $\mathrm{Cl}, 59.43 \mathrm{kcal} / \mathrm{mol}$ for $\mathrm{O}$, $171.21 \mathrm{kcal} / \mathrm{mol}$ for $\mathrm{C}$, and $112.94 \mathrm{kcal} / \mathrm{mol}$ for $\mathrm{N})$. The $a b$ initio energies of the atoms were corrected to account for spin-orbit coupling using the experimental spin-orbit interaction energies $(0.2136 \mathrm{kcal} / \mathrm{mol}$ for $\mathrm{Al}, 0.8396 \mathrm{kcal} /$ $\mathrm{mol}$ for $\mathrm{Cl}, 0.2230 \mathrm{kcal} / \mathrm{mol}$ for $\mathrm{O}$, and 0.0847 $\mathrm{kcal} / \mathrm{mol}$ for C [26]). Petersson et al. [27] have presented an assessment of the accuracy of the three methods used here, along with several others, for the group of molecules that they called the "G2-1,2 neutral molecule test set". For this collection of around 150 molecules with well established experimental heats of formation, the B3LYP, CBS-Q, and G2 methods used here had mean absolute deviations of 3.43, 1.19, and $1.43 \mathrm{kcal} / \mathrm{mol}$, respectively, between the calculated and experimental heats of formation. The corresponding root mean square deviations 
between calculation and experiment were 5.17, 1.77 , and $2.04 \mathrm{kcal} / \mathrm{mol}$. Based on these results, we would expect the calculated enthalpies of formation obtained from the B3LYP calculations to be accurate to within \pm 3 to $5 \mathrm{kcal} / \mathrm{mol}$, and would expect those calculated using the $\mathrm{G} 2$ and CBS-Q methods to be accurate to within \pm 1 to $2 \mathrm{kcal} / \mathrm{mol}$. However, the set of molecules considered here contains several polychlorides, for which the CBS-Q method is known to perform poorly [27]. Our results also show larger than expected differences between the CBS-Q and G2 methods for the aluminum oxides. This indicates that at least one of those two methods has lower accuracy for the aluminum oxides than for the set of molecules considered by Petersson et al. [27]. Without more precise experimental thermochemical data for the gas-phase aluminum oxide species, it is not possible to establish which method, CBS-Q or $\mathrm{G} 2$, performs better for this class of compounds. While the energies obtained with the B3LYP method used here are less reliable than the other two methods, these calculations have been included because they are much less computationally expensive, and can therefore be applied to larger molecules for which the CBS-Q and G2 methods cannot be used. The frequency calculations from the B3LYP method, done at the B3LYP/6-31G(d) level, are expected to be more accurate than those from the CBS-Q and G2 methods, which compute the frequencies at the HF/6-31G(d') and HF/6-31G(d) levels, respectively. We have therefore reported the B3LYP/6-31G(d) frequencies here. These have been scaled by 0.9613 as recommended by Wong [28] for frequencies calculated at this level.

\section{Al GASEOUS SPECIES OF INTEREST FOR COMBUSTION MODELING PURPOSES}

The following species have been observed during $\mathrm{Al}$ combustion under various experimental conditions (particle combustion, laser ablation, etc.) or above solid or liquid alumina at high temperatures. Relevant atmospheres are the intermediates and final products of solid propellants: $\mathrm{CO}_{2}, \mathrm{HCl}, \mathrm{N}_{2}$, etc.
To date, experimental studies have dealt principally with $\mathrm{Al}$ in $\mathrm{O}_{2}$, despite the fact that there is little molecular oxygen in the typical solid propellant combustion products. Some have considered $\mathrm{Al}$ in $\mathrm{CO}_{2}$ or $\mathrm{Al}$ in $\mathrm{CO}$ as well. However, during practical applications, $\mathrm{HCl}$ and $\mathrm{H}_{2} \mathrm{O}$ are also produced. Therefore the aluminum hydrides, aluminum chlorides, and aluminum chlorohydrides must also be considered, even though most of them have not been observed in classical aluminum particle combustion experiments. Likewise, the $\mathrm{Al} / \mathrm{O} / \mathrm{H}$ species (such as $\mathrm{AlOH}$ ) and $\mathrm{Al} / \mathrm{O} / \mathrm{Cl}$ species (such as $\mathrm{OAlCl}$ ) should be considered. The likely presence of these species during aluminum combustion is deduced primarily from elementary kinetic studies.

Electronically excited species are also of interest. Although not yet demonstrated in the case of $\mathrm{Al}$ particle combustion, the kinetic role of excited species has been shown to be important in many other combustion systems. For example, the importance of singlet $\mathrm{CH}_{2}$ in hydrocarbon combustion is well established [29]. In $\mathrm{Al}$ particle combustion this can also be the case since the temperatures reached are high ( 2300 to about $4500 \mathrm{~K}$ ). Therefore, in addition to the ground state of each species, we have also considered the lowest-energy state of different spin multiplicity for many of the compounds. In many cases, the spin multiplicity of the ground state was not known a priori, and these calculations were necessary to determine which spin state corresponded to the ground state. Excited states with the same spin multiplicity as the ground state were not considered.

\section{Aluminum Oxides}

$\mathrm{AlO}$ has been observed by Yuasa et al. in $\mathrm{Al} / \mathrm{CO}_{2}$ experiments using $\mathrm{AlO}$ emission spectroscopy in the visible range [30], by Bucher et al. [31] using AlO laser-induced fluorescence (LIF), by Driscoll et al. [32] using AlO emission spectroscopy, and by Vanpée et al. [33] in trimethylaluminum-oxygen flames, among others. AlO has been identified mass spectrometrically to be a vapor species above solid alumina [34]. AlO has also been identified in matrix isolation studies [35] and as a product of the 
reactions of pulsed-laser evaporated aluminum atoms with oxygen [36].

$\mathrm{AlO}_{2}$ has been shown mass spectrometrically to be a minor vapor species above alumina [37]. It has been detected by Mann and Weaver [38] mass spectrometrically in the $\mathrm{Al} / \mathrm{O}_{2}$ reaction system. One gas-phase study of this molecule has been performed by Desai et al. [39]. It is a product of the reactions of pulsed-laser evaporated aluminum atoms with molecular oxygen [36]. It has been proposed as a product of the reaction between $\mathrm{AlO}$ and $\mathrm{O}_{2}$ [40]. Fontijn [16] has pointed out that it is necessary to distinguish between the possible isomers of $\mathrm{AlO}_{2}$ ( $\mathrm{AlOO}$ or $\mathrm{OAlO}$ ). There is evidence for the formation of both linear and cyclic $\mathrm{AlO}_{2}$ [36].

$\mathrm{Al}_{2} \mathrm{O}_{2}$ has been detected mass spectrometrically in the vapor over alumina [41, 42]. It is a product of the reactions of pulsed-laser evaporated aluminum atoms with molecular oxygen [36]. Theoretical studies have considered several possible structures for $\mathrm{Al}_{2} \mathrm{O}_{2}$ [43].

$\mathrm{Al}_{2} \mathrm{O}$ has been detected mass spectrometrically in the vapor over alumina [34]. It has been detected by fluorescence spectroscopy in the gas phase [44] and also by IR spectroscopy in the gas phase [45].

\section{Aluminum Hydrides, Aluminum Chlorides, and Aluminum Chlorohydrides}

Elementary kinetic studies have shown that $\mathrm{AlCl}$ (and not $\mathrm{AlH}$ ) is one of the products of the reaction between $\mathrm{Al}$ and $\mathrm{HCl}$ [46] as well as the reaction between $\mathrm{Al}$ and $\mathrm{Cl}_{2}$ [46]. The same authors considered the reaction between $\mathrm{AlCl}$ and $\mathrm{Cl}_{2}$ with $\mathrm{AlCl}_{2}$ and $\mathrm{Cl}$ as products. Slavejkov and Fontijn proposed $\mathrm{AlCl}_{2}$ as a product of $\mathrm{AlCl}+\mathrm{HCl}$ [47]. According to recent theoretical calculations on the $\mathrm{Al}+\mathrm{HCl}$ system, the products should be $\mathrm{AlCl}$ or $\mathrm{HAlCl}$, depending on the angle of attack of the $\mathrm{Al}$ atom on the $\mathrm{HCl}$ molecule [48, 49]. The species $\mathrm{AlHCl}_{2}$ has been observed in matrix isolation studies [50]. $\mathrm{AlCl}_{3}$ is a stable compound and has been observed in the gas phase by Klemperer [51], among others.

Although aluminum chlorides are formed more readily, formation of $\mathrm{AlH}$ and other aluminum hydrides $\left(\mathrm{AlH}_{2}\right.$ and $\left.\mathrm{AlH}_{3}\right)$ cannot be excluded. $\mathrm{AlH}$ is the predicted product of the reaction $\mathrm{H}+\mathrm{AlCl}$, according to the calculations of Garrett and Truhlar [52]. Pasternack and Rice [53] studied the reactions of $\mathrm{AlH}$ with several species, including $\mathrm{O}_{2}, \mathrm{H}_{2} \mathrm{O}$, and $\mathrm{H}_{2}$ at $300 \mathrm{~K}$ by following the LIF of $\mathrm{AlH}$. They propose several reaction paths for the reactions $\mathrm{AlH}+\mathrm{O}_{2}$ and $\mathrm{Al}+\mathrm{H}_{2} \mathrm{O} \cdot \mathrm{AlH}_{2}$ has been observed as a gas-phase species by Herzberg [54] and in matrix isolation studies by Parnis and Ozin [55]. $\mathrm{AlH}, \mathrm{AlH}_{2}$, and $\mathrm{AlH}_{3}$ have been observed as products of the reactions of pulsedlaser ablated $\mathrm{Al}$ atoms with $\mathrm{H}_{2}$ [56].

\section{OAICI, AIOH, HAIOH}

Slavejkov et al. [57] found that $\mathrm{OAlCl}$ is one of the products of the reaction $\mathrm{AlO}+\mathrm{HCl}$ and $\mathrm{AlO}+\mathrm{Cl}_{2}$. The same authors reported that $\mathrm{AlOH}$ was produced competitively with $\mathrm{OAlCl}$ during the reaction between $\mathrm{AlO}$ and $\mathrm{HCl}$. $\mathrm{OAlCl}$ is also a product of the reactions $\mathrm{AlCl}+$ $\mathrm{O}_{2}$ [58] and $\mathrm{AlCl}+\mathrm{CO}_{2}$ [59]. McClean et al. [60] performed kinetic experiments on the reaction of $\mathrm{Al}$ in its ground state with $\mathrm{H}_{2} \mathrm{O}$ by following the $\mathrm{LIF}$ of $\mathrm{Al}$ atoms. Their experiments are compatible with the presence of two reaction channels, one producing $\mathrm{AlOH}$ via excited $\mathrm{HAlOH}$, the other yielding $\mathrm{AlO}$.

\section{Aluminum Nitrides and Aluminum Carbides}

The existence of aluminum nitrides during the combustion of $\mathrm{Al}$ particles in an $\mathrm{O}_{2} / \mathrm{N}_{2}$ environment has been studied by Bucher et al. [7]. Gas-phase AlN may exist above $2550 \mathrm{~K}$ during aluminum combustion. The same authors have observed the presence of condensed carboncontaining species [presumably formed from $\mathrm{AlC}(\mathrm{g})]$ throughout the gas phase during the combustion of $\mathrm{Al}$ particles in $\mathrm{CO}$ atmosphere. Linear AlCN and AlNC have been observed during the reaction of $\mathrm{Al}$ atoms with $\mathrm{HCN}$ by combining the laser-ablation, matrix isolation, and Fourier transform infrared (FTIR) spectroscopy techniques [61].

\section{RESULTS AND DISCUSSION}

The final results of the calculations are summarized in Tables 1 and 2. The optimized geometries and the total energies calculated using 
TABLE 1

Moments of Inertia and Scaled ${ }^{a}$ B3LYP/6-31G(d) Vibrational Frequencies

\begin{tabular}{|c|c|c|c|}
\hline Species & Spin State & Vibrational Frequencies $\left(\mathrm{cm}^{-1}\right)^{c}$ & Moments of Inertia (amu $\AA^{2}$ ) \\
\hline $\mathrm{AlH}$ & Singlet & 1586 & 2.7 \\
\hline $\mathrm{AlH}$ & Triplet & 1668 & 2.5 \\
\hline $\mathrm{AlH}_{2}$ & Doublet & 73617431788 & 1.33 .85 .1 \\
\hline $\mathrm{AlH}_{2}$ & Quartet & 66611171367 & 1.54 .15 .6 \\
\hline $\mathrm{AlH}_{3}$ & Singlet & 679 757(2) $18551869(2)$ & 3.83 .87 .6 \\
\hline $\mathrm{AlCl}$ & Singlet & 442 & 72 \\
\hline $\mathrm{AlCl}$ & Triplet & 469 & 70 \\
\hline $\mathrm{AlCl}_{2}$ & Doublet & 139425536 & 23235258 \\
\hline $\mathrm{AlCl}_{2}$ & Quartet & 183270381 & 66135201 \\
\hline $\mathrm{AlCl}_{3}$ & Singlet & 142(2) $190363592(2)$ & 229229457 \\
\hline $\mathrm{AlO}$ & Doublet & 913 & 27 \\
\hline $\mathrm{AlO}$ & Quartet & 646 & 33 \\
\hline $\mathrm{OAlO}^{b}$ & Doublet & 178195745799 & 85 \\
\hline $\mathrm{OAlO}^{b}$ & Quartet & 285804857 & 273966 \\
\hline Cyclic $\mathrm{AlO}_{2}$ & Doublet & 3445111142 & 155064 \\
\hline Cyclic $\mathrm{AlO}_{2}$ & Quartet & 4455881115 & 154661 \\
\hline $\mathrm{AlOAl}$ & Singlet & $88(2) 486935$ & 161 \\
\hline $\mathrm{AlOAl}$ & Triplet & 249640715 & 1791108 \\
\hline $\mathrm{Al}_{2} \mathrm{O}_{2}$ & Singlet & 292491527588731759 & 5380133 \\
\hline $\mathrm{Al}_{2} \mathrm{O}_{2}$ & Triplet & 262496584697705745 & 5380133 \\
\hline $\mathrm{AlOAlO}$ & Singlet & $48(2) 217(2) 4449081146$ & 301 \\
\hline $\mathrm{AlOH}$ & Singlet & 1228043751 & 0.133333 \\
\hline $\mathrm{OAlCl}$ & Singlet & 155(2) 4601077 & 164 \\
\hline $\mathrm{OAlCl}$ & Triplet & 154474727 & 18129148 \\
\hline $\mathrm{AlHCl}$ & Doublet & 4695421733 & 2.07375 \\
\hline $\mathrm{AlHCl}_{2}$ & Singlet & 1564284555556411946 & 28228256 \\
\hline $\mathrm{AlH}_{2} \mathrm{Cl}$ & Singlet & 49549658075318931913 & 4.07579 \\
\hline $\mathrm{Al}_{2} \mathrm{O}_{3}$ & Singlet & 34(2) 166(2) 240(2) 41089911071198 & 500 \\
\hline $\mathrm{Al}_{2} \mathrm{O}_{3} \mathrm{C} 2 \mathrm{v}$ & Singlet & 53562242373936147388711100 & 22382404 \\
\hline $\mathrm{OAlH}$ & Singlet & 388(2) 10381929 & 31 \\
\hline $\mathrm{OAlOH}$ & Singlet & 18619455073511303704 & 0.589293 \\
\hline $\mathrm{OAlOH}$ & Triplet & 1592065796858273686 & 137487 \\
\hline $\mathrm{AlC}^{b}$ & Doublet & 732 & 28 \\
\hline $\mathrm{AlC}$ & Quartet & 610 & 32 \\
\hline AlN & Singlet & 904 & 26 \\
\hline AlN & Triplet & 714 & 30 \\
\hline $\mathrm{AlCN}$ & Singlet & $169(2) 4482174$ & 103 \\
\hline $\mathrm{AlCN}$ & Triplet & 2413055362116 & 94 \\
\hline AlNC & Singlet & 110(2) 5312037 & 87 \\
\hline AlNC & Triplet & 1692325881993 & 83 \\
\hline
\end{tabular}

${ }^{a}$ Calculated frequencies were scaled by a factor of 0.9613 .

${ }^{b}$ Calculation showed some spin contamination at this level; see text for details.

${ }^{c}$ (2) indicates doubly degenerate frequencies.

each method are not presented, but are available from the authors upon request. The normal mode vibrational frequencies, which were used in the calculation of the thermochemical properties, are given in Table 1. The standard enthalpies of formation obtained based on the B3LYP, CBS-Q, and G2 calculations are given in Table 2. Enthalpies of formation from the
CBS-RAD method are also given for several of the molecules that have ground states with spin multiplicity greater than one. For a few of the species, the molecular orbital calculations exhibited significant spin contamination. These species are noted in Tables 1 and 2, and discussed individually below. The effect of spin contamination on heats of formation calculated 
TABLE 2

Calculated Enthalpies of Formation ${ }^{a}$

\begin{tabular}{|c|c|c|c|c|c|c|}
\hline Species & Spin State & $\begin{array}{c}\Delta_{\mathrm{f}} \mathrm{H}^{\circ}{ }_{298 \mathrm{~K}} \\
\text { B3LYP }\end{array}$ & $\begin{array}{c}\Delta_{\mathrm{f}} \mathrm{H}^{\circ}{ }_{298 \mathrm{~K}} \\
\text { CBS-Q }\end{array}$ & $\begin{array}{c}\Delta_{\mathrm{f}} \mathrm{H}_{298 \mathrm{~K}}^{\circ} \\
\mathrm{G} 2\end{array}$ & $\begin{array}{c}\Delta_{\mathrm{f}} \mathrm{H}^{\circ}{ }_{298 \mathrm{~K}} \\
\text { CBS-RAD }\end{array}$ & $\begin{array}{c}\Delta_{\mathrm{f}} \mathrm{H}^{\circ}{ }_{298 \mathrm{~K}} \\
\text { Experimental }\end{array}$ \\
\hline $\mathrm{AlH}$ & Singlet & 59.5 & 58.2 & 57.7 & & $62 \pm 5$ \\
\hline $\mathrm{AlH}$ & Triplet & 103.1 & 103.2 & 104.2 & & $c$ \\
\hline $\mathrm{AlH}_{2}$ & Doublet & 61.8 & 62.4 & 63.1 & 63.5 & $c$ \\
\hline $\mathrm{AlH}_{2}$ & Quartet & 143.9 & 143.7 & 145.1 & 145.1 & $c$ \\
\hline $\mathrm{AlH}_{3}$ & Singlet & 30.6 & 29.5 & 29.1 & & $c$ \\
\hline $\mathrm{AlCl}$ & Singlet & -9.1 & -15.4 & -12.9 & & $\begin{array}{l}\text { In the range } \\
-10 \text { to }-17.78\end{array}$ \\
\hline $\mathrm{AlCl}$ & Triplet & 60.7 & 54.7 & 58.3 & & $c$ \\
\hline $\mathrm{AlCl}_{2}$ & Doublet & -46.8 & -57.4 & -51.8 & -57.3 & $-67 \pm 5$ \\
\hline $\mathrm{AlCl}_{2}$ & Quartet & 69.0 & 62.2 & 70.0 & & $c$ \\
\hline $\mathrm{AlCl}_{3}$ & Singlet & -126.8 & -146.3 & -139.8 & & $-139.72 \pm 0.69$ \\
\hline $\mathrm{AlO}$ & Doublet & 18.9 & $17.0^{d}$ & $18.8^{d}$ & $18.8^{d}$ & $16 \pm 2$ \\
\hline $\mathrm{AlO}$ & Quartet & 100.1 & 99.0 & 101.2 & 104.6 & $c$ \\
\hline OAlO & Doublet & $-13.4^{d}$ & -15.9 & -10.2 & -14.8 & $-20.6 \pm 8.0$ \\
\hline OAlO & Quartet & $34.8^{d}$ & $32.4^{d}$ & $38.4^{d}$ & $33.1^{d}$ & $c$ \\
\hline Cyclic- $\mathrm{AlO}_{2}$ & Doublet & 11.1 & $8.8^{d}$ & $11.7^{d}$ & $10.6^{d}$ & $c$ \\
\hline Cyclic- $\mathrm{AlO}_{2}$ & Quartet & 81.1 & $78.0^{d}$ & $81.7^{d}$ & $77.8^{d}$ & $c$ \\
\hline $\mathrm{AlOAl}$ & Singlet & -28.2 & -38.7 & -35.6 & & $-34.7 \pm 4.0$ \\
\hline $\mathrm{AlOAl}$ & Triplet & 37.4 & $31.2^{d}$ & $37.9^{d}$ & & $c$ \\
\hline $\mathrm{Al}_{2} \mathrm{O}_{2}$ & Singlet & -74.0 & -94.5 & -87.9 & & $-94.3 \pm 8.0$ \\
\hline $\mathrm{Al}_{2} \mathrm{O}_{2}$ & Triplet & -68.4 & -82.6 & -74.9 & & $c$ \\
\hline AlOAlO & Singlet & -71.3 & -87.7 & -80.3 & & $c$ \\
\hline $\mathrm{AlOH}$ & Singlet & -40.0 & -45.5 & -43.8 & & $-43 \pm 3^{b}$ \\
\hline $\mathrm{AlOH}$ & Triplet & 32.5 & 27.5 & 30.1 & & $c$ \\
\hline $\mathrm{OAlCl}$ & Singlet & -48.2 & -60.3 & -54.7 & & $-82.2 \pm 5.0^{b}$ \\
\hline $\mathrm{OAlCl}$ & Triplet & -9.9 & 17.1 & 22.3 & & $c$ \\
\hline $\mathrm{AlHCl}$ & Doublet & 6.1 & 1.5 & 4.7 & 1.6 & $c$ \\
\hline $\mathrm{AlHCl}{ }_{2}$ & Singlet & -77.1 & -89.8 & -85.6 & & $c$ \\
\hline $\mathrm{AlH}_{2} \mathrm{Cl}$ & Singlet & -24.1 & -30.7 & -28.8 & & $c$ \\
\hline Linear $\mathrm{Al}_{2} \mathrm{O}_{3}$ & Singlet & -106.9 & -130.0 & -118.4 & & $c$ \\
\hline $\mathrm{Al}_{2} \mathrm{O}_{3} \mathrm{C} 2 \mathrm{v}$ & Singlet & -81.1 & -101.7 & -94.0 & & $c$ \\
\hline $\mathrm{OAlH}$ & Singlet & 189.9 & 189.9 & 189.9 & & $8 \pm 20^{b}$ \\
\hline $\mathrm{OAlOH}$ & Singlet & -198.4 & -210.8 & -202.9 & & $-110 \pm 15^{b}$ \\
\hline $\mathrm{OAlOH}$ & Triplet & -159.3 & -162.4 & -159.1 & & $c$ \\
\hline $\mathrm{AlC}$ & Doublet & $201.7^{d}$ & $195.1^{d}$ & $201.1^{d}$ & $195.5^{d}$ & $164.8 \pm 2.4^{b}$ \\
\hline $\mathrm{AlC}$ & Quartet & 172.5 & 171.5 & 172.8 & 171.7 & $c$ \\
\hline AlN & Singlet & 154.5 & 136.4 & 135.3 & 140.9 & $c$ \\
\hline $\mathrm{AlN}$ & Triplet & 128.0 & $132.6^{d}$ & $134.6^{d}$ & $131.3^{d}$ & $125 \pm 9$ \\
\hline $\mathrm{AlCN}$ & Singlet & 71.4 & 69.9 & 70.8 & & $c$ \\
\hline $\mathrm{AlCN}$ & Triplet & 126.0 & 125.3 & 126.2 & & $c$ \\
\hline AlNC & Singlet & 65.0 & 63.4 & 63.9 & & $c$ \\
\hline AlNC & Triplet & 130.4 & 129.7 & 131.5 & & $c$ \\
\hline
\end{tabular}

${ }^{a}$ Units are $\mathrm{kcal} \mathrm{mol}^{-1}$.

${ }^{b}$ Rough estimate according JANAF tables.

${ }^{c}$ No data given in JANAF tables.

${ }^{d}$ Calculation showed some spin contamination at this level; see text for details.

using the G2 and CBS-Q methods was investigated by Mayer et al. [25]. They found that for severely spin-contaminated species, the CBS-Q method performed better than the G2 method, and that the $\mathrm{G} 2$ method could be in error by as much as $5 \mathrm{kcal} / \mathrm{mol}$ for the most highly spincontaminated species. For most of the species with open-shell ground states, we have also applied the CBS-RAD method recommended by Mayer et al. [25]. For most of the species 
considered here, the B3LYP calculations of the frequencies did not exhibit significant spin contamination, and therefore the frequencies reported in Table 1 are expected to be reliable. Both the G2 and CBS-Q methods have been shown to reproduce the known heats of formation of 166 species with an average error of about $1 \mathrm{kcal} \mathrm{mol}^{-1}$ [62]. The thermodynamic data presented here may be obtained in the NASA (CHEMKIN) format from the authors upon request.

For these compounds, we find that there is a somewhat larger difference between the heats of formation from the CBS-Q method and the other methods than would be expected based on previous work. An analysis of the results presented by Petersson et al. [27] shows that for the approximately 150 compounds considered there, the average difference between heats of formation from the G2 method and the CBS-Q method was $0.3 \mathrm{kcal} / \mathrm{mol}$, and the average absolute difference was $1.3 \mathrm{kcal} / \mathrm{mol}$. For the 41 aluminum compounds considered here, the average difference was $3.6 \mathrm{kcal} / \mathrm{mol}$ and the average absolute difference was $3.7 \mathrm{kcal} / \mathrm{mol}$. Thus, for these compounds the CBS-Q method is systematically predicting lower heats of formation than the G2 method, and this is contrary to our expectations based on the work of Petersson et al. [27]. The difference between the heats of formation predicted by the B3LYP method and by the G2 method is more consistent with expectations. For the compounds considered by Petersson et al. [27] the average difference was $-1.5 \mathrm{kcal} / \mathrm{mol}$ and the average absolute difference was $3.4 \mathrm{kcal} / \mathrm{mol}$. For the molecules considered here, the average difference was -2.1 $\mathrm{kcal} / \mathrm{mol}$ and the average absolute difference was $4.8 \mathrm{kcal} / \mathrm{mol}$. Thus, the differences seen here are slightly, but not dramatically, larger than those observed in the calculations of Petersson et al. As implied by the above observations, the differences between the CBS-Q and B3LYP predictions for the thermochemistry are larger than expected. For the molecules studied by Petersson et al. the average difference was $-1.8 \mathrm{kcal} / \mathrm{mol}$ and the average absolute difference was $3.6 \mathrm{kcal} / \mathrm{mol}$. For the compounds considered here, the average difference was $-5.8 \mathrm{kcal} / \mathrm{mol}$ and the average absolute difference was $7.3 \mathrm{kcal} / \mathrm{mol}$. This confirms that the
CBS-Q method is systematically predicting lower heats of formation than the other two methods. Based on this, we can tentatively recommend the values from the G2 method. We applied the CBS-RAD method recommended by Mayer et al. [25] to 14 of the species with open-shell ground states. The average difference between the G2 and CBS-RAD methods was $1.8 \mathrm{kcal} / \mathrm{mol}$, while the average difference between the CBS-Q and CBS-RAD methods was $-1.2 \mathrm{kcal} / \mathrm{mol}$. The corresponding average absolute differences were 3.1 and 1.4 $\mathrm{kcal} / \mathrm{mol}$, respectively. So, on average, the CBSRAD values fell in between those from the CBS-Q and G2 methods.

$\operatorname{AlCl}_{n}(n=1,2,3)$

Petrie [63] has previously presented results of $a b$ initio calculations on the thermochemistry of aluminum halides.

\section{$\mathrm{AlCl}_{3}$}

Of the species considered here, the enthalpy of formation $\left(\Delta_{\mathrm{f}} \mathrm{H}^{\circ}\right)$ at $298.15 \mathrm{~K}$ of the molecule $\mathrm{AlCl}_{3}$ is the most well known. A value of $-139.72 \pm 0.69 \mathrm{kcal} \mathrm{mol}^{-1}$ is given in the JANAF tables [64]. The G2 calculations provide a value of $-139.81 \mathrm{kcal} \mathrm{mol}^{-1}$, which agrees very well with the experimental value. This result has previously been presented several times, since $\mathrm{AlCl}_{3}$ is included in the $\mathrm{G} 2$ test set which has been widely used for evaluation of $a b$ initio methods of predicting molecular energies [27]. It is known that the CBS-Q method performs poorly for polychlorides [27], and this is illustrated again here.

\section{$\mathrm{AlCl}_{2}$}

The JANAF tables provide a $\Delta_{\mathrm{f}} \mathrm{H}^{\circ}{ }_{298.15}$ value of $-67.0 \pm 4.8 \mathrm{kcal} \mathrm{mol}^{-1}$. Our results from all three $a b$ initio methods disagree with the recommended JANAF value. This is the same conclusion reached by Petrie [63]. Since the JANAF recommendation is not considered reliable by the authors themselves [64], we recommend the heat of formation predicted by the G2 calculations. 


\section{AlCl}

The calculations with the G2 model provide a $\Delta_{\mathrm{f}} \mathrm{H}^{\circ}{ }_{298.15}$ value of $-12.9 \mathrm{kcal} \mathrm{mol}{ }^{-1}$ which agrees very well with the JANAF recommendation of $-12.3 \pm 1.5 \mathrm{kcal} \mathrm{mol}^{-1}$.

\section{$\mathrm{AlH}_{n}(n=1,2,3)$}

No values for $\Delta_{\mathrm{f}} \mathrm{H}_{298.15}^{\circ}$ are recommended in the JANAF tables for $\mathrm{AlH}_{2}$ or $\mathrm{AlH}_{3}$. Curtiss et al. [21] performed ab initio calculations on $\mathrm{AlH}$, $\mathrm{AlH}_{2}$, and $\mathrm{AlH}_{3}$ but they did not extract enthalpies of formation from their calculations.

\section{AlH}

A heat of formation of $61.97 \mathrm{kcal} \mathrm{mol}^{-1}$ is given in the CHEMKIN thermodynamic data base [65]. This value is about $4 \mathrm{kcal} \mathrm{mol}^{-1}$ higher than the results presented here. The JANAF tables give a value of $62 \pm 5 \mathrm{kcal} \mathrm{mol}^{-1}$, a result consistent with the one given here.

\section{$\mathrm{AlH}_{2}$}

A heat of formation of $41.93 \mathrm{kcal} \mathrm{mol}^{-1}$ can be found in the CHEMKIN thermodynamic data base [65]. Our results disagree with this value. Without knowing the source of the value in the CHEMKIN database, it is not possible to explain the discrepancy.

\section{$\mathrm{AlH}_{3}$}

A value of $18.82 \mathrm{kcal} \mathrm{mol}^{-1}$ for the heat of formation of $\mathrm{AlH}_{3}$ is given in the CHEMKIN thermodynamic data base [65]. Our results disagree with this value. Without knowing the source of the value in the CHEMKIN database, it is not possible to explain the discrepancy. In another computational study, a value of 29.4 $\mathrm{kcal} \mathrm{mol}^{-1}$ was reported by Ochterski et al. [62] who used methods very similar to those used here.

\section{$\mathrm{AlH}_{x} \mathrm{Cl}_{y}(x, y=1,1 ; 1,2 ; 2,1)$}

The values computed for the species $\mathrm{AlHCl}$, $\mathrm{AlHCl}_{2}$, and $\mathrm{AlH}_{2} \mathrm{Cl}$ are given without comment since we are aware of no previously pub- lished experimental or theoretical studies of the thermochemistry of these species.

$$
\mathrm{Al}_{x} \mathrm{O}_{y}(x, y=1,1 ; 1,2 ; 2,1 ; 2,2 ; 2,3)
$$

\section{AlO}

Several values can be found in the literature for the $\Delta_{\mathrm{f}} \mathrm{H}^{\circ}{ }_{298.15}$ of $\mathrm{AlO}$. Although widely observed in $\mathrm{Al}$ particle combustion experiments, $\mathrm{AlO}$ has not previously been the subject of published theoretical studies. The calculations performed here are consistent with the value of $16 \pm 2 \mathrm{kcal}$ $\mathrm{mol}^{-1}$ recommended by the JANAF tables and with the value of $16.5 \pm 2.0 \mathrm{kcal} \mathrm{mol}^{-1}$ given by Srivastava and Farber [66]. Our results are also consistent with the value of $21.8 \mathrm{kcal} \mathrm{mol}^{-1}$ given by Wagman et al. [67] to within the combined uncertainties. In fact, the value obtained here appears to be intermediate between the ones given in the literature. The remaining discrepancies, though small, may be of importance for combustion modeling purposes since $\mathrm{AlO}$ is one of the major species present during the combustion process. The doublet state of AlO exhibited slight spin contamination. The B3LYP calculations had $\left\langle S^{2}\right\rangle \approx 0.76$, compared to the ideal $\left\langle S^{2}\right\rangle$ for a doublet of 0.75 . The component calculations in the CBS-Q and G2 methods had $\left\langle S^{2}\right\rangle$ of 0.79 to 0.80 . This slight spin contamination is not expected to impact the accuracy of the CBS-Q and G2 methods [25]. This is verified by the CBS-RAD results which are in good agreement with the other methods.

\section{$\mathrm{AlO}_{2}$}

Linear OAlO. There is a considerable disagreement in the literature on $\Delta_{\mathrm{f}} \mathrm{H}^{\circ}{ }_{298.15}$ of $\mathrm{AlO}_{2}$. The JANAF tables recommend a value of $-20.6 \pm 7.6 \mathrm{kcal} \mathrm{mol}^{-1}$ whereas Lias et al. [68] give a value of $-31 \mathrm{kcal} \mathrm{mol}^{-1}$ and Srivastava and Farber [66] a value of $-44.9 \pm 3 \mathrm{kcal}$ $\mathrm{mol}^{-1}$. Our calculations predict a heat of formation slightly higher than that recommended in the JANAF tables. The ground state of this molecule was predicted to be linear by all of the calculations. The B3LYP calculations predicted equal lengths for the $\mathrm{Al}-\mathrm{O}$ bonds, while the others predicted an asymmetric structure with one bond about $0.15 \AA$ longer than the other one. The B3LYP calculations exhibited slight 
spin contamination, with $\left\langle S^{2}\right\rangle \approx 0.79$ compared to $\left\langle S^{2}\right\rangle=0.75$ for a pure doublet state. The other calculations showed very little spin contamination, with $\left\langle S^{2}\right\rangle$ less than 0.76 in all cases. For the quartet state, a bent structure is predicted. Again, the B3LYP calculations exhibited slight spin contamination, with $\left\langle S^{2}\right\rangle \approx 3.79$ compared to $\left\langle S^{2}\right\rangle=3.75$ for a pure quartet state. The component calculations in the CBSQ and G2 methods showed greater spin contamination, with $\left\langle S^{2}\right\rangle \approx 4.00$. For this molecule, we also applied the CBS-RAD methodology. This gave a heat of formation in good agreement with the other methods, but closer to the CBSQ results than to the $\mathrm{G} 2$ results.

Cyclic $\mathrm{AlO}_{2}$. We also considered the cyclic $\mathrm{AlO}_{2}$ structure, and found that its heat of formation was 22 to $24 \mathrm{kcal} \mathrm{mol}^{-1}$ higher than the linear OAlO structure. The minimum energy cyclic $\mathrm{AlO}_{2}$ structure had $\mathrm{Al}-\mathrm{O}$ bond lengths of about $1.95 \AA$ and an O-O bond length of about $1.35 \AA$, but these varied significantly between calculation levels. The geometry optimizations at the HF/6-31G(d) and B3LYP/6$31 \mathrm{G}(\mathrm{d})$ levels gave a structure with equal Al-O bond lengths. However, the optimization at the QCISD/6-31G(d) level gave a distorted structure with one Al-O bond about $0.07 \AA$ longer than the other one. Frequency calculations confirmed that these structures were true minima, and that the structure with equal $\mathrm{Al}-\mathrm{O}$ bond lengths was a saddle point at the QCISD/6$31 \mathrm{G}(\mathrm{d})$ level. The calculations used in the CBS-Q and G2 methods exhibited slight spin contamination for both the doublet and quartet states of this molecule. The doublet state calculations had $\left\langle S^{2}\right\rangle$ of 0.78 to 0.79 , and the quartet state had $\left\langle S^{2}\right\rangle$ of 3.77 to 3.78 . The minor spin contamination and the slight geometry difference between the structures optimized at different levels did not significantly impact the accuracy of the CBS-Q and G2 methods. This is confirmed by the results obtained using the CBS-RAD methodology.

Linear AlOO. Fontijn [16] noted that the $\mathrm{AlO}_{2}$ formed in different experiments could be different species, namely $\mathrm{OAlO}, \mathrm{AlOO}$, and cyclic $\mathrm{AlO}_{2}$. Andrews et al. [36] found no evidence for the formation of any $\mathrm{AlO}_{2}$ species other than linear $\mathrm{OAlO}$ and cyclic $\mathrm{AlO}_{2}$. There are apparently no studies reported in the literature dealing with the thermochemistry of AlOO. Geometry optimizations and frequency calculations at the $\mathrm{HF} / 6-31 \mathrm{G}(\mathrm{d})$, B3LYP/631G(d), and QCISD/6-31G(d) levels agreed that the linear structure is a second-order saddle point on the ground state (doublet) potential energy surface. Following the minimum energy path (intrinsic reaction coordinate) away from this saddle point at the HF/6-31G(d) level led to the cyclic $\mathrm{AlO}_{2}$ structure discussed above, without crossing any potential barriers. The saddle point corresponding to the minimum energy linear structure was about $15 \mathrm{kcal} / \mathrm{mol}$ higher in energy than the cyclic structure.

\section{$\mathrm{Al}_{2} \mathrm{O}$}

Our calculations provide a result consistent with the recommended value of $-34.7 \pm 4.1 \mathrm{kcal}$ $\mathrm{mol}^{-1}$ given in the JANAF tables for AlOAl. Nemukhin and Weinhold [43] studied the structure of $\mathrm{AlOAl}$ and $\mathrm{AlAlO}$ by ab initio methods. They concluded that AlAlO is a stable linear molecule but that it is $80 \mathrm{kcal} / \mathrm{mol} \mathrm{higher} \mathrm{in}$ energy than AlOAl and cannot be formed in combustion experiments. The component calculations of the CBS-Q and G2 calculations for the triplet state of AlOAl exhibited slight spin contamination, with $\left\langle S^{2}\right\rangle$ of 2.04 to 2.05 compared to the ideal value of $\left\langle S^{2}\right\rangle=2.0$ for a triplet state.

\section{$\mathrm{Al}_{2} \mathrm{O}_{2}$}

Nemukhin and Weinhold [43] studied the possible structures for $\mathrm{Al}_{2} \mathrm{O}_{2}$. They located seven possible geometries, but only three of them were low enough in energy that they can be considered as possible candidates for the ground state of the $\mathrm{Al}_{2} \mathrm{O}_{2}$ species. These are the singlet and triplet, cyclic, almost-square, planar $\mathrm{Al}_{2} \mathrm{O}_{2}$, and the singlet linear AlOAlO. Nemukhin and Weinhold did not derive enthalpies of formation for these species from their calculations. The JANAF tables give a $\Delta_{\mathrm{f}} \mathrm{H}^{\circ}{ }_{298.15}$ value of $-94.3 \pm 7.6 \mathrm{kcal} \mathrm{mol}^{-1}$ for the singlet state of the square-planar structure. Our calculations provide values that are consistent with this recommendation. No published value has been found for the linear $\mathrm{AlOAlO}$ structure. The CBS-Q and G2 models give 
values of $-87.69 \mathrm{kcal} \mathrm{mol}^{-1}$ and $-80.27 \mathrm{kcal}$ $\mathrm{mol}^{-1}$, respectively, for the enthalpy of formation (see Table 2) of this species, only about 7 $\mathrm{kcal} \mathrm{mol}{ }^{-1}$ higher than our calculations for the square-planar structure.

\section{$\mathrm{Al}_{2} \mathrm{O}_{3}$}

An important process in aluminum combustion is the formation of liquid alumina $\left(\mathrm{Al}_{2} \mathrm{O}_{3}\right)$, accompanied by considerable heat release. However, there are some controversies about the nature of the gaseous species that condense to give liquid alumina. It has been concluded for years that liquid alumina boils with decomposition and that $\mathrm{Al}_{2} \mathrm{O}_{3}$ does not exist in the gas phase under experimental conditions (temperature and pressure) encountered in $\mathrm{Al}$ particle combustion studies. This does not mean that gaseous alumina does not exist in other experimental conditions since gaseous $\mathrm{Al}_{2} \mathrm{O}_{3}$ has been observed by Desai et al. [39] in a plasma containing $\mathrm{O}_{2}$ and aluminum atoms in both neutral and charged states. This situation is not encountered in $\mathrm{Al}$ particle combustion studies where only neutral $\mathrm{Al}$ atoms exist. According to Desai et al. [39], $a b$ initio calculations have predicted three gaseous alumina structures: linear OAlOAlO and two structures with $\mathrm{C}_{2 \mathrm{v}}$ symmetry. Nemukhin and Weinhold [43] found that the linear OAlOAlO structure was the lowest energy conformation, and that a planar structure with $\mathrm{C}_{2 \mathrm{v}}$ symmetry had an energy about 11 $\mathrm{kcal} / \mathrm{mol}$ above that of the linear isomer. They also found other isomers, but those were all 30 $\mathrm{kcal} / \mathrm{mol}$ or more above the linear isomer. A recent aluminum particle combustion model [14] included the condensation of gaseous alumina to form liquid alumina. Calculations have been performed here for the linear OAlOAlO structure and the planar $\mathrm{C}_{2 \mathrm{v}}$ structure briefly described above.

$$
\mathrm{Al}_{x} \mathrm{O}_{y} \mathrm{H}_{z}(x, y, z=1,1,1 ; 1,1,1 ; 1,2,1)
$$

\section{$\mathrm{AlOH}$}

The computed value of the enthalpy of formation at $298.15 \mathrm{~K}$ of this compound is in good agreement with the value of $-43.0 \pm 3.1 \mathrm{kcal}$ $\mathrm{mol}^{-1}$ recommended by Chase [69].

\section{OAIH, OAIOH}

Our calculations disagree with those recommended in the JANAF tables for these two species. However, the JANAF table recommendations are presented as rough estimates, rather than experimental measurements. Therefore, based on the accuracy of the methods used here and our agreement with experiment for the other compounds, we conclude that the JANAF table recommendations are not reliable for these two compounds.

\section{AlN}

According to JANAF tables, the triplet state is the ground state. Our calculations also give the triplet state as the ground state but predict that the triplet and singlet states are separated by only a few $\mathrm{kcal} / \mathrm{mol}$. Our predicted enthalpy of formation is consistent with that given in the JANAF tables. The calculations for the triplet state of AlN showed slight spin contamination. The B3LYP calculations had $\left\langle S^{2}\right\rangle \approx 2.02$, compared to the ideal value for a triplet of $\left\langle S^{2}\right\rangle$ $=2.0$. The component calculations of the CBS-Q and G2 methods had $\left\langle S^{2}\right\rangle$ of 2.06 to 2.08. This slight spin contamination is not expected to significantly impact the accuracy of the CBS-Q and G2 methods [25]. Since the ground state of this molecule is the triplet, we also applied the CBS-RAD method to it. The results are in rough agreement with the other methods, but predict a somewhat larger energy difference between the singlet and triplet states than the CBS-Q and G2 methods.

\section{AlC}

The predicted ground state from our calculations is a quartet rather than a doublet. The ground state according to the JANAF tables is a doublet. The calculations and the value given in the JANAF tables for the enthalpy of formation do not agree but there is only weak experimental support for the JANAF recommendation. Our calculations for the doublet state of this species exhibited severe spin contamination, but this is not surprising since the ground state is the quartet state. The B3LYP calculations for the doublet state had $\left\langle S^{2}\right\rangle \approx 1.0$, compared to the 
ideal $\left\langle S^{2}\right\rangle$ for a doublet of 0.75 . The component calculations in the CBS-Q and G2 methods had $\left\langle S^{2}\right\rangle \approx 2.35$. The quartet state did not exhibit significant spin contamination. All of the methods had $\left\langle S^{2}\right\rangle$ less than 3.76 for the quartet state, compared to the ideal value of 3.75. Application of the CBS-RAD method to AlC gave results consistent with the other methods.

\section{AlNC, AlCN}

The values computed for the species AINC and $\mathrm{AlCN}$ are given without comment since we are aware of no previously published experimental or theoretical studies of the thermochemistry of these species.

Standard entropies and heat capacities were also calculated for all of the species considered here. These may be obtained from the authors upon request. In general, where reliable experimental results were available, the computed entropies and heat capacities agreed with the experimental values to within the error limits of the experimental results.

\section{EQUILIBRIUM CALCULATIONS}

As pointed out by Steinberg et al. [70], thermochemical data like those presented here are useful for understanding combustion of metals. Constant-pressure adiabatic flame temperature and the corresponding equilibrium composition have been computed using the aluminum oxide species and thermochemical data proposed here. The heats of formation based on the G2 calculations were used in these equilibrium calculations. These results were compared to the predictions obtained using the species and thermodynamic data previously available ( $\mathrm{Al}, \mathrm{AlO}$, $\mathrm{AlO}_{2}, \mathrm{Al}_{2} \mathrm{O}, \mathrm{Al}_{2} \mathrm{O}_{2}$, and liquid $\mathrm{Al}_{2} \mathrm{O}_{3}$ with data from the tables of Burcat and McBride [71], which they obtained from the JANAF tables [64]). Table 3 gives the results obtained in both cases for a mixture of $20 \mathrm{~mol} \% \mathrm{Al}(\mathrm{g}), 15 \mathrm{~mol} \%$ $\mathrm{O}_{2}$, and $65 \mathrm{~mol} \% \mathrm{Ar}$ at an initial pressure and temperature of $0.1 \mathrm{MPa}$ and $2300 \mathrm{~K}$, respectively. At this temperature of $2300 \mathrm{~K}$, liquid $\mathrm{Al}$ vaporizes vigorously and reacts with $\mathrm{O}_{2}$ in the gas phase. The EQUIL equilibrium code from the CHEMKIN III collection was used for the computations [72]. The mixture taken here is
TABLE 3

Equilibrium Composition ${ }^{a}$

\begin{tabular}{|c|c|c|}
\hline \multirow[b]{2}{*}{ Species } & \multicolumn{2}{|c|}{ Mole Fraction } \\
\hline & $\begin{array}{l}\text { Previous } \\
\text { Thermochemistry }^{b}\end{array}$ & $\begin{array}{l}\text { Recommended } \\
\text { Thermochemistry }\end{array}$ \\
\hline $\mathrm{Al}(\mathrm{g})$ & $4.910^{-2}$ & $3.410^{-2}$ \\
\hline $\mathrm{O}$ & 0.125 & 0.137 \\
\hline $\mathrm{O}_{2}$ & $2.010^{-2}$ & $2.710^{-2}$ \\
\hline $\mathrm{AlO}^{d}$ & $8.110^{-2}$ & $4.510^{-2}$ \\
\hline $\mathrm{AlO}^{e}$ & $h$ & $1.610^{-6}$ \\
\hline $\mathrm{OAlO}^{d}$ & $8.810^{-4 i}$ & $1.210^{-4}$ \\
\hline $\mathrm{OAlO}^{e}$ & $h$ & $9.310^{-7}$ \\
\hline Cyclic $\mathrm{AlO}_{2}{ }^{d}$ & $h$ & $1.410^{-5}$ \\
\hline Cyclic $\mathrm{AlO}_{2}^{e}$ & $h$ & $1.410^{-9}$ \\
\hline $\mathrm{AlOAl}^{f}$ & $2.510^{-2}$ & $5.610^{-2}$ \\
\hline $\mathrm{AlOAl}^{g}$ & $h$ & $5.510^{-6}$ \\
\hline $\mathrm{Al}_{2} \mathrm{O}_{2}^{f}$ & $2.510^{-3 i}$ & $1.810^{-4}$ \\
\hline $\mathrm{Al}_{2} \mathrm{O}_{2}^{g}$ & $h$ & $8.310^{-5}$ \\
\hline AlOAlO & $h$ & $6.210^{-3}$ \\
\hline $\mathrm{Al}_{2} \mathrm{O}_{3}$ & $h$ & $4.310^{-5}$ \\
\hline $\mathrm{Al}_{2} \mathrm{O}_{3} \mathrm{C}_{2 \mathrm{v}}$ & $h$ & $1.610^{-6}$ \\
\hline $\mathrm{Al}_{2} \mathrm{O}_{3}(\ell)$ & $1.210^{-2}$ & $4.510^{-3}$ \\
\hline $\mathrm{Ar}$ & 0.684 & 0.690 \\
\hline
\end{tabular}

${ }^{a}$ For initial conditions of $20 \% \mathrm{Al}(\mathrm{g}), 15 \% \mathrm{O}_{2}$, and $65 \%$ Ar at $0.1 \mathrm{MPa}$ and $2300 \mathrm{~K}$.

${ }^{b}$ Using data from reference [71], predicted flame temperature is $3750 \mathrm{~K}$.

${ }^{c}$ Using data from this work, predicted flame temperature is $3729 \mathrm{~K}$.

${ }^{d}$ Doublet state.

${ }^{e}$ Quartet state.

${ }^{f}$ Singlet state.

$g$ Triplet state.

${ }^{h}$ Not included in these calculations.

${ }^{i}$ Previous thermochemistry did not specify the isomer or electronic state of this species.

not one that would be encountered during real applications. However, the aim here was to test a simple mixture where the diluent does not play a role chemically. This would not be the case if $\mathrm{N}_{2}$ were the diluent. The recommended thermochemistry predicts an adiabatic flame temperature of $3729 \mathrm{~K}$ for these conditions. This is almost the same temperature as the prediction using the thermochemistry previously available. There are, however, substantial differences in the composition between the two cases. Concerning the new species introduced in the calculations, it appears that $\mathrm{Al}_{2} \mathrm{O}_{3}$ is formed at the liquid state. The formation of gaseous alumina is found to be negligible. The other forms of $\mathrm{AlO}_{2}$ than linear OAlO are produced in negligibly small quantities. The linear form of 
$\mathrm{Al}_{2} \mathrm{O}_{2}(\mathrm{AlOAlO})$ is produced in greater quantities than the square-planar form.

These computations can readily be extended to the much higher pressures of several MPa that are encountered in real applications.

\section{CONCLUSIONS}

This study provides thermochemical data needed for the construction of detailed kinetic models of the combustion of $\mathrm{Al}$ particles under practical conditions and experimental conditions (especially for the systems other than $\mathrm{Al} / \mathrm{O})$. Some of the species considered here have previously been neglected or assumed to be unimportant for aluminum combustion. Thermochemical data presented here will allow their importance, or lack thereof, to be demonstrated. Experimental measurements of the heats of formation are required to resolve discrepancies between the predictions of the different $a b$ initio methods employed here and to provide reliable thermochemical data for some of the aluminum oxide species that have not previously been studied. However, the methods used here provide thermochemical parameters of sufficient accuracy to provide a self-consistent, preliminary database for construction of models of aluminum combustion that include detailed chemistry. These models can be used to identify the most crucial species, for which additional experimental and theoretical studies can be carried out. Future computational chemistry work will extend these thermochemical predictions to reaction paths and transition states. This will allow identification of the most important reactions, as well as the most important species, for aluminum combustion. Preliminary comparisons of equilibrium predictions from the thermochemical parameters recommended here and from those previously available, show that there are significant differences in the predicted equilibrium composition.

L. C. thanks B. Legrand, Dr. I. Gökalp, and Prof. C. Paillard for helpful discussions.

\section{REFERENCES}

1. Belyaev, A. F., Frolov, Y. V., and Korotkov, A. I., Combust. Explos. Shock Waves 4:182 (1968).

2. Kuehl, D. K., AIAA J. 3:2239 (1965).

3. Friedman, R., and Macek, A., Ninth Symposium (International) on Combustion, The Combustion Institute, Pittsburgh, 1963, p. 703; Macek, A., Eleventh Symposium (International) on Combustion, The Combustion Institute, Pittsburgh, 1967, p. 203.

4. Marion, M., Chauveau, C., and Gökalp, I., Combust. Sci. Technol. 115:369 (1996).

5. Merzhanov, A. G., Grigorjev, Y. M., and Gal'chenko, Y. A., Combust. Flame 29:1 (1977).

6. Yuasa, S., and Isoda, H., Twenty-Second Symposium (International) on Combustion, The Combustion Institute, Pittsburgh, 1988, p. 1635.

7. Bucher, P., Yetter, R. A., Dryer, F. L., Vicenzi, E. P., Parr, T. P., and Hanson-Parr, D. M., Combust. Flame 117:351 (1999).

8. Price, E. W., AIAA Prog. Astronaut. Aeronaut. 90:479 (1983).

9. Bartlett, R. W., Ong, J. N., Fassell, W. M., and Papp, C. A., Combust. Flame 7:227 (1963).

10. Brzustowski, T. A., and Glassman, I., AIAA Prog. Astronaut. Aeronaut. 15:75 (1964).

11. Kudryavtsev, V. M., Sukhov, A. V., Voronetskii, A. V., and Shpara, A. P., Combust. Explos. Shock Waves 15:731 (1979).

12. Law, C. K., Combust. Sci. Technol. 7:197 (1973).

13. Brooks, K. P., and Beckstead, M. W., J. Propuls. Power 11:769 (1995).

14. Liang, Y., and Beckstead, M. W. (1998). 36th Aerospace Sciences Meeting and Exhibit, AIAA.

15. King, M. K., Seventeenth Symposium (International) on Combustion, The Combustion Institute, Pittsburgh, 1978, p. 1317.

16. Fontijn, A., Combust. Sci. Technol. 50:151 (1986).

17. Becke, A. D., Phys. Rev. A 38:3098 (1988).

18. Lee, C., Yang, W., and Parr, R. G., Phys. Rev. B 37:785 (1988).

19. Becke, A. D., J. Chem. Phys. 98:5648 (1993).

20. Ochterski, J. W., Petersson, G. A., and Wiberg, K. B., J. Am. Chem. Soc. 117:11299 (1995).

21. Curtiss, L. A., Raghavachari, K., Trucks, G. W., and Pople, J. A., J. Chem. Phys. 94:7221 (1991).

22. Curtiss, L. A., Raghavachari, K., and Pople, J. A., J. Chem. Phys. 98:1293 (1993).

23. Curtiss, L. A., Redfern, P. C., Smith, B. J., and Radom, L., J. Chem. Phys. 104:5148 (1996).

24. Frisch, M. J., Trucks, G. W., Schlegel, H. B., et al., Gaussian 94 (Revision D.4), Gaussian, Inc., Pittsburgh, 1995.

25. Mayer, P. M., Parkinson, C. J., Smith, D. M., and Radom, L., J. Chem. Phys. 108:604 (1998).

26. Moore, C., Natl. Bur. Stand. (U.S.) Circ. 467 (1952).

27. Petersson, G. A., Malick, D. K., Wilson, W. G., Ochterski, J. W., Montgomery, J. A., and Frisch, M. J., J. Chem. Phys. 109:10570 (1998).

28. Wong, M. W., Chem. Phys. Lett. 256:391 (1996). 
29. Miller, J. A., and Bowman, C. T., Prog. Energy Combust. Sci. 15:287 (1989).

30. Yuasa, S., Sogo, S., and Isoda, H., Twenty-Fourth Symposium (International) on Combustion, The Combustion Institute, Pittsburgh, 1992, p. 1817.

31. Bucher, P., Yetter, R. A., Dryer, F. L., Parr, T. P., Hanson-Parr, D. M., and Vicenzi, E. P., Twenty-Sixth Symposium (International) on Combustion, The Combustion Institute, Pittsburgh, 1996, p. 1899.

32. Driscoll, J. F., Nicholls, J. A., Patel, V., Shahihi, B. K., and Liu, T. C., AIAA J. 24:856 (1986).

33. Vanpée, M., Hinck, E. C., and Seamans, T. F., Combust. Flame, 9:393 (1965).

34. Burns, R. P., J. Chem. Phys. 44:3307 (1966).

35. Bares, S. J., Haak, M., and Nibler, J. W., J. Chem. Phys. 82:670 (1985).

36. Andrews, L., Burkholder, T. R., and Yustein, J. T., J. Phys. Chem. 96:10182 (1992).

37. Ho, P., and Burns, R. P., High. Temp. Sci. 12:31 (1980).

38. Mann, D. M., and Weaver, D. P. (1984). AFRPL Technical Report 84-53.

39. Desai, S. R., Wu, H., Rohlfing, C. M., and Wang, L.-S., J. Chem. Phys. 106:1309 (1997).

40. Belyung, D. P., and Fontijn, A., J. Phys. Chem. 99: 12225 (1995).

41. Drowart, J., DeMaria, G., Burns, R. P., and Inghram, M. G., J. Chem. Phys. 32:1366 (1960).

42. King, F. L., Dunlap, B. I., and Parent, D. C., J. Chem. Phys. 94:2578 (1991).

43. Nemukhin, A. V., and Weinhold, F., J. Chem. Phys. 97:3420 (1992).

44. Cai, M., Carter, C. C., Miller, T. A., and Bondybey, V. E., J. Chem. Phys. 95:73 (1991).

45. Linevski, M. J., White, D., and Mann, D. E., J. Chem. Phys. 41:542 (1964).

46. Rogowski, D. F., Marshall, P., and Fontijn, A., J. Phys. Chem. 93:1118 (1989).

47. Slavejkov, A. G., and Fontijn, A., Chem. Phys. Lett. 165:375 (1990).

48. Köppe, R., and Kasai, P. H., J. Am. Chem. Soc. 118:134 (1996).

49. Fängström, T., Lunell, S., Kasai, P. H., and Eriksson, L. A., J. Phys. Chem. A 102:1005 (1998).

50. Schnockel, H., J. Mol. Struct. 50:275 (1978).

51. Klemperer, W., J. Chem. Phys. 24:353 (1956).

52. Garrett, B. C., and Truhlar, D. G., J. Am. Chem. Soc. 101:5207 (1979).

53. Pasternack, L., and Rice, J. K., J. Phys. Chem. 95:8701 (1991).
54. Herzberg, G., Molecular Spectra and Molecular Structure, III. Electronic Spectra and Electronic Structure of Polyatomic Molecules, Van Nostrand Reinhold, New York, 1966.

55. Parnis, J. M., and Ozin, G. A., J. Phys. Chem. 93:1215 (1989).

56. Chertihin, G. V., and Andrews, L., J. Phys. Chem. 97:10295 (1993).

57. Slavejkov, A. G., Stanton, C. T., and Fontijn, A., J. Phys. Chem. 94:3347 (1990).

58. Rogowski, D. F., and Fontijn, A., Twenty-First Symposium (International) on Combustion, The Combustion Institute, Pittsburgh, 1986, p. 943.

59. Rogowski, D. F., and Fontijn, A., Chem. Phys. Lett. 132:413 (1986).

60. McClean, R. E., Nelson, H. H., and Campbell, M. L., J. Phys. Chem. 97:9673 (1993).

61. Lanzisera, D. V., and Andrews, L., J. Phys. Chem. A 101:9660 (1997).

62. Ochterski, J. W., Petersson, G. A., and Wiberg, K. B., J. Am. Chem. Soc. 117:11299 (1995).

63. Petrie, S., J. Phys. Chem. A 102:7828 (1998).

64. Chase, M. W., Davies, C. A., Downey, J. R., Frurip, D. J., McDonald, R. A., and Syverud, A. N., J. Phys. Chem. Ref. Data vol. 14(suppl. 1) 1:1896 (1985).

65. Kee, R. J., Rupley, F. M., and Miller, J. A., (1990). The Chemkin Thermodynamic Data Base, Sandia National Laboratories Rept. SAND87-8215B.

66. Srivastava, R. D., and Farber, M., Chem. Rev. 78:627 (1978).

67. Wagman, D. D., Evans, W. H., Parker, V. B., Schumm, R. H., Halow, I., Bailey, S. M., Churney, K. L., and Nuttall, R. L., J. Phys. Chem. Ref. Data 11(suppl. 2) 1:394 (1982).

68. Lias, S. G., Bartmess, J. E., Liebman, J. F., Holmes, J. L., Levin, R. D., and Mallard, W. G., J. Phys. Chem. Ref. Data 17(suppl. 1) 1:268 (1988).

69. Chase, M. W. (1998) NIST-JANAF Thermochemical Tables, 4th ed., J. Phys. Chem. Ref. Data Monograph 9 1:1951.

70. Steinberg, T. A., Wilson, D. B., and Benz, F., Combust. Flame 91:200 (1992).

71. Burcat, A., and McBride, B. (1997). Ideal Gas Thermodynamic Data for Combustion and Air-Pollution Use. Technion-Israel Institute of Technology, TAE 804.

72. Lutz, A. E., Rupley, F. M., Kee, R. J., and Reynolds, W. C. (1998). EQUIL: A Chemkin Implementation of Stanjan for Computing Chemical Equilibria. Reaction Design, Inc., San Diego, CA. 